\title{
EXPERIMENTAL STUDY TO EVALUATE THE HYDRAULIC PERFORMANCE OF BASTORA DAM STEPPED SPILLWAY
}

\author{
SARHANG M. HuSAin ${ }^{*}$ and SHAhIN S. AHMED ${ }^{* *}$ \\ *Dept. of Dams And Water Resources, College of Engineering, University of Salahaddin, Kutdistan Region-Iraq \\ ** Dept. of Dams And Water Resources, College of Engineering, University of Salahaddin, Kutdistan Region-Iraq
}

\begin{abstract}
This study aims to evaluate the performance of proposed design for Bastora dam stepped spillway project. Experiments are conducted on a physical model, which is constructed at the laboratory of hydraulic engineering/ college of engineering/ Salahaddin University, Erbil- Iraq using an appropriate scale to avoid potential effects governing the model. The evaluation includes determining the flow regime passing the structure, length to and flow depth at the inception point, the efficiency of the structure to dissipate the energy at the toe, the height of side wall required for both the spillway chute and stilling basin at the downstream of the spillway and discharge coefficient. The results presented in the design report are compared with those measured/determined in this study and the design formulae of stepped spillway available in the literature. Although the comparisons show few discrepancies between the results, especially in terms of the energy dissipation rate and chute side wall dimension, the design report can be said acceptable and reliable.
\end{abstract}

KEYWORDS: Physical Modelling, Bastora Dam Stepped Spillway, Discharge Coefficient, Energy Dissipation.

\section{INTRODUCTION}

D am spillways are designed to release excess water during times of peak flow. Water flows to the toe of the dam having high kinetic energy which may damage the structure (Chow, 1959). Stepped spillways have been widely designed and constructed over the past few decades as protection measures to stand against such damage (Chanson, 2002). Therefore, a relatively smaller size of stilling basin is required to be built at the downstream to dissipate the residual energy. The use of stepped spillways goes back more than 3500 years, when the oldest structure of this type was built in Akarnania, Greece (Chanson, 1995). Normally, steps of different dimensions, configurations and arrangements are introduced into the surface of the conventional smooth spillway and arranged in such a way to provide a staircase shape profile from top to bottom. The flow over stepped spillways is complex and characterized by high velocity and high turbulence levels, and contains high amounts of air in the aerated flow region (Chanson, 1997). Depending on the discharge and step geometry, flow over stepped spillways has been classified into three regimes: nappe flow which occurs with low flow rates; skimming flow dealing with relatively high discharges; and transition flow with moderate discharges (Chanson, 2002).

In the recent years, Kurdistan Region Government has planned to construct a number of small, medium and few large dams to store and control the excess water in the region. Bastora dam is one of these dams designed by ERGES Engineering and Consulting Ltd.
Co. in 2007. The Bastora dam site is located at in Gomaspan Gorge about $30 \mathrm{Km}$ to the NE of Erbil City in Kurdistan Region.

This study concerns evaluation of the hydraulic performance of Bastora dam stepped spillways. This is accomplished by constructing a physical model at the laboratory of hydraulic engineering/ college of engineering/ Salahaddin University, Erbil- Iraq using an appropriate scale to avoid scale effects on the experimental results. The evaluation includes determining the flow regime passing the structure, length to and flow depth at the inception point, the efficiency of the structure to dissipate the energy at the toe, the height of side wall required for both the spillway chute and stilling basin at the downstream of the spillway and discharge coefficient.

\section{LITERATURE REVIEW}

Flow over stepped spillways has been investigated extensively using both laboratory experiments and numerical simulations. However, only a limited number of studies is available in the literature regarding the physical model studies, namely; Peyras et al. (1992) for modelling stepped gabions, Rice and Kadavy (1996) for modelling RCC stepped spillways, Gonzalez (2005) for modelling air- water flow on embankment dams, Hunt et al. (2007) who performed experiments on a physical model to characterize the flow over Renwick dam RCC stepped spillway. These 
studies are performed on stepped spillways having steep, mild and flat slopes and under different flow conditions to find the main design key elements and provide more definitive and detailed guidelines required in the design of this type of hydraulic structures (Hunt and Kadavy, 2010).

Chanson (2001) analysed a large number of experimental records regarding the change of flow conditions on stepped spillways of bottom slopes ranging between $3.4^{\circ}$ and $60^{\circ}$ and the following two equations are proposed to define the upper and lower limits of the nappe and skimming flow conditions respectively:

$\frac{y_{c}}{h_{s}}=0.89-0.4\left(\frac{h_{s}}{l_{s}}\right)$
$\frac{y_{c}}{h_{s}}=1.20-0.325 \frac{h_{s}}{l_{s}}$

where, $y_{c}$ is the critical flow depth above the spillway crest and $h_{s}$ and $l_{s}$ are the step height and length respectively. In fact these two equations are used in the design report to predict the flow conditions over Bastora dam stepped spillway. Further, with flow rates corresponding to the skimming flow condition, chanson (1994) stated that natural air entrainment or self-aeration initiates at a point on the stepped spillway where the turbulent boundary layer is fully developed and its outer edge intersects the free surface; this point is termed the inception point of air entrainment. This point is the start of the apparition of "white water" on the chute. Different empirical equations have been proposed to determine the coordinate of this point. However, the design report used the following two equations, which are proposed by Boes and Minor (2002) for chute slopes ranging $26^{\circ}<\theta<75^{\circ}$, to find the length to and depth at the inception point of air entrainment respectively:

$\begin{aligned} L_{i} & =\frac{5.90 y_{c}^{1.2}}{(\sin \theta)^{1.4} h_{s}^{0.2}} \\ d_{i} & =\frac{0.4 y_{c}^{0.9} h_{s}^{0.1}}{(\sin \theta)^{0.3}}\end{aligned}$

in which $L_{i}$ and $d_{i}$ represent the length to and depth of flow at the inception point of air entrainment respectively and $\theta$ is the chute slope.

The enhanced energy dissipation is one of the most attractive features of stepped spillways which may take place on the steps along the chute slope. Numerous investigations have been performed and different empirical equations and charts to estimate the energy dissipation and/ or the residual energy at the toe of the stepped spillways. Chanson (2002) pointed out that the energy loss can be calculated from the difference in energy between the inlet section at the approach channel of spillway $\mathrm{H}_{1}$ and any section of the step of interest $\mathrm{H}_{\mathrm{i}}$ at downstream as shown in Figure 1.

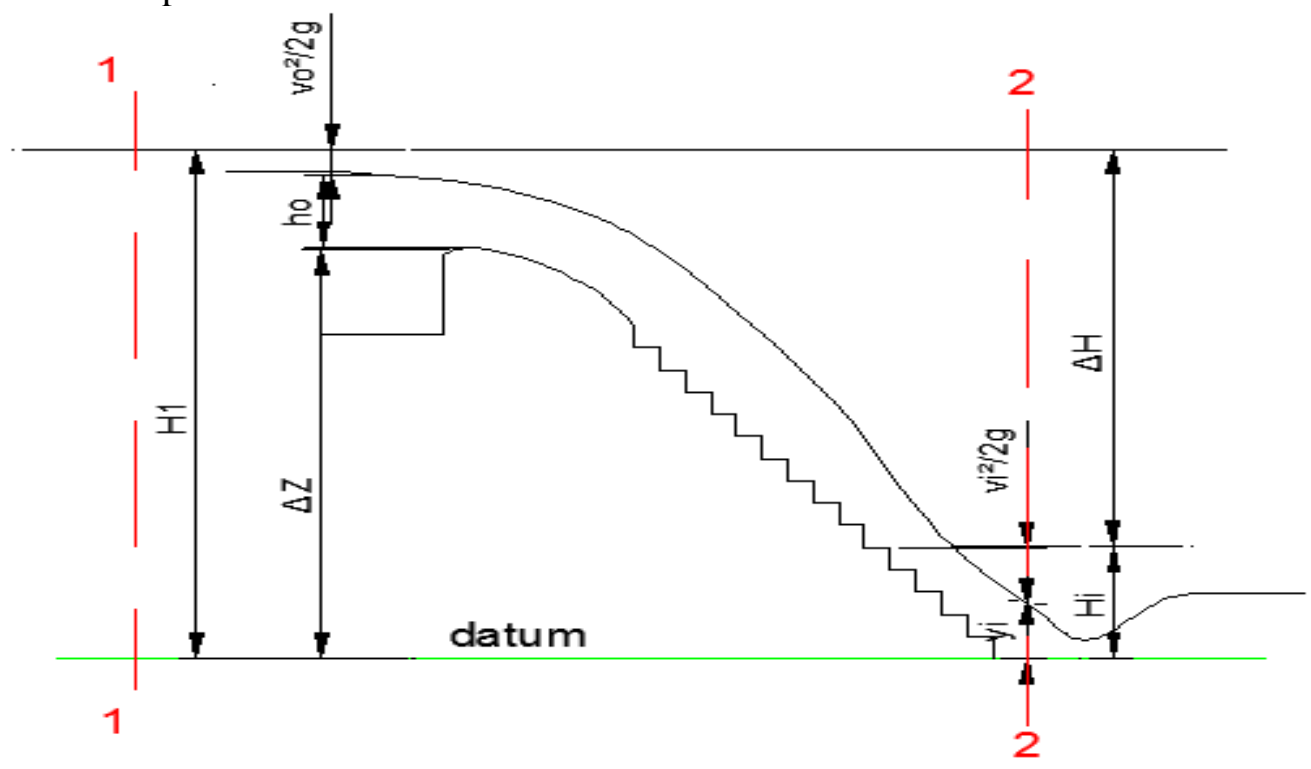

Fig. (1): Energy loss parameters as they relate to the stepped spillway.

The energy loss between any two sections may be calculated in the following way. Given section
(1-1) and (2-2) for example, in section (1-1) the total energy $\mathrm{H}_{1}$ consists of: 


$$
\mathrm{H}_{1}=\Delta \mathrm{Z}+\mathrm{h}_{\mathrm{o}}+\frac{\mathrm{v}_{\mathrm{o}}^{2}}{2 \mathrm{~g}}
$$

where, $\Delta \mathrm{Z}$ is the difference in elevation between both sections, $h_{o}$ and $v_{o}$ are respectively is the mean flow depth and mean flow velocity at section 1. In section (2-2), the step of interest is also superimposed with datum. Consequently, the energy $\mathrm{Hi}$ is given by the flow depth measured vertically from the datum $y_{i}$ and the velocity head $\mathrm{v}_{\mathrm{i}}{ }^{2} / 2 \mathrm{~g}$.

$\mathrm{H}_{\mathrm{i}}=\mathrm{y}_{\mathrm{i}}+\alpha \frac{\mathrm{v}_{\mathrm{i}}^{2}}{2 \mathrm{~g}}$

$\Delta \mathrm{H}=\mathrm{H}_{1}-\mathrm{H}_{\mathrm{i}}$

The relative energy dissipation $\Delta \mathrm{H} / \mathrm{H}_{1}$ between $\mathrm{U} / \mathrm{S}$ and $\mathrm{D} / \mathrm{S}$ of stepped spillways, is one of the dimensionless parameter which has been widely used to study the performance of the structure in dissipating the flow energy (Chanson, 2002).

In many open channel applications where the channel is of regular cross-section, the energy coefficient $(\alpha)$ is assumed to equal unity because the effect of non-uniform velocity distribution on the computed velocity head is small (Chow, 1959. To evaluate the performance of the stepped spillway and the stilling basin, the energy loss will be calculated at both structures. It is worth mentioning here that these concepts and equations are used by a number of researchers to estimate the energy dissipation rate on stepped spillways, namely; Yasuda et al. (2001), Chatila et al. (2004), Gonzalez (2005), Karim Jumaily et al. (2009), Hunt and Kadavy, (2010) and Felder and Chanson (2011). This allows us to use the same equations in the current work to estimate the energy dissipation rate on the physical model of Bastora dam stepped spillway.

\section{EXPERIMENTAL WORK SET UP AND APPARATUSES}

\section{A) Description of the physical model}

The hydraulic performance in free surface flow models primarily depends on gravitational and inertia forces (Chow, 1959). According to the U.S. Bureau of Reclamation (USBR), it is recommended that models of large dams and spillways be constructed to scale ratios of $1: 30$ to $1: 100$, while for medium-size structures the models should not be smaller than 1:60 scale and flow heads larger than $3 \mathrm{~cm}$ should be used in order to avoid surface tension problems (Chatila \& Jurdi, 2004). Furthermore, Chanson (1999) recommended 1:25 to 1:50 scale model of an open channel to eliminate scale effects. Boes and Hager (2003) proposed a minimum value for Reynolds and Weber numbers of 105 and 100 respectively to avoid scale effects of viscous and surface tension forces in air-water flow like that expected to occur in stepped spillways. Takahashi et al. (2006) stated that Froude, Reynolds and Morton similarities for modelling air- water flow can only be met at full scale model. Based on the facilities which exist at the Hydraulic Laboratory, the scale of this physical model was selected as 1:40. Figure 2 shows the general schematic diagram of the physical model.

The experimental work of this study is conducted at the Hydraulic Laboratory of the Civil Engineering Department at Salahaddin University, Erbil in Kurdistan Region. The spillway model is consisted of an ogee shape crest of $0.8(\mathrm{H}): 1(\mathrm{~V})$ slope, stepped chute at the downstream built from high density plastic Perspex sheets (acrylic) with a thickness of $6 \mathrm{~mm}$ to make the flow behaviour in the model visible as shown in Figure 2. The spillway is designed based on the equations recommended by the US Bureau of Reclamation (USBR, 1987). The slops profile consists of 70 steps starting at somehow distance from the crest. Three small step sizes are used in the upper portion of the chute slope just behind the weir crest to reduce splash of water drops while flowing over the steps. These steps are followed by 67 identical steps of larger size $2.8 \mathrm{~cm}$ in height and $1.2 \mathrm{~cm}$ in length to the end of the chute slope. Figure 3 shows the general schematic diagram of the physical model in which the dimensions are obtained based on geometric similarity. Table 1 shows the characteristics of the dam, spillway and stilling basin of the prototype model of Bastora dam. Besides, all the dimensions of the stepped spillway physical model are presented in Table 2. 


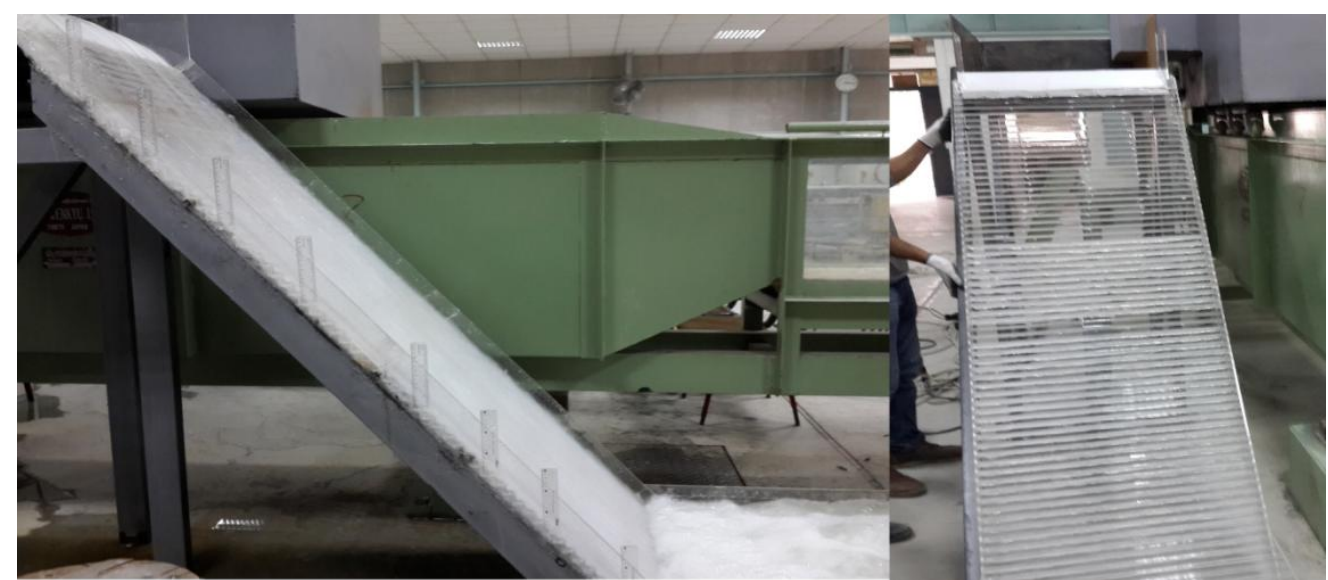

Fig. (2): Physical model of Bastora dam Spillway stepped.

\section{B) Apparatuses and experimental work set up}

An underground concrete storage tank with a capacity of $18 \mathrm{~m}^{3}$ is used to supply water for the model. In addition, an electro pump with a capacity of $0.05 \mathrm{~m}^{3} / \mathrm{sec}$ is used to transfer water, through a 6-inch pipe, from the underground concrete storage tank to the overhead tank which is located upstream of the model, see Figure 4. A tank made of thick steel plates with the inner dimensions $3.7 \mathrm{~m}$ in length, $0.8 \mathrm{~m}$ in width and $0.6 \mathrm{~m}$ in depth is used as a reservoir to

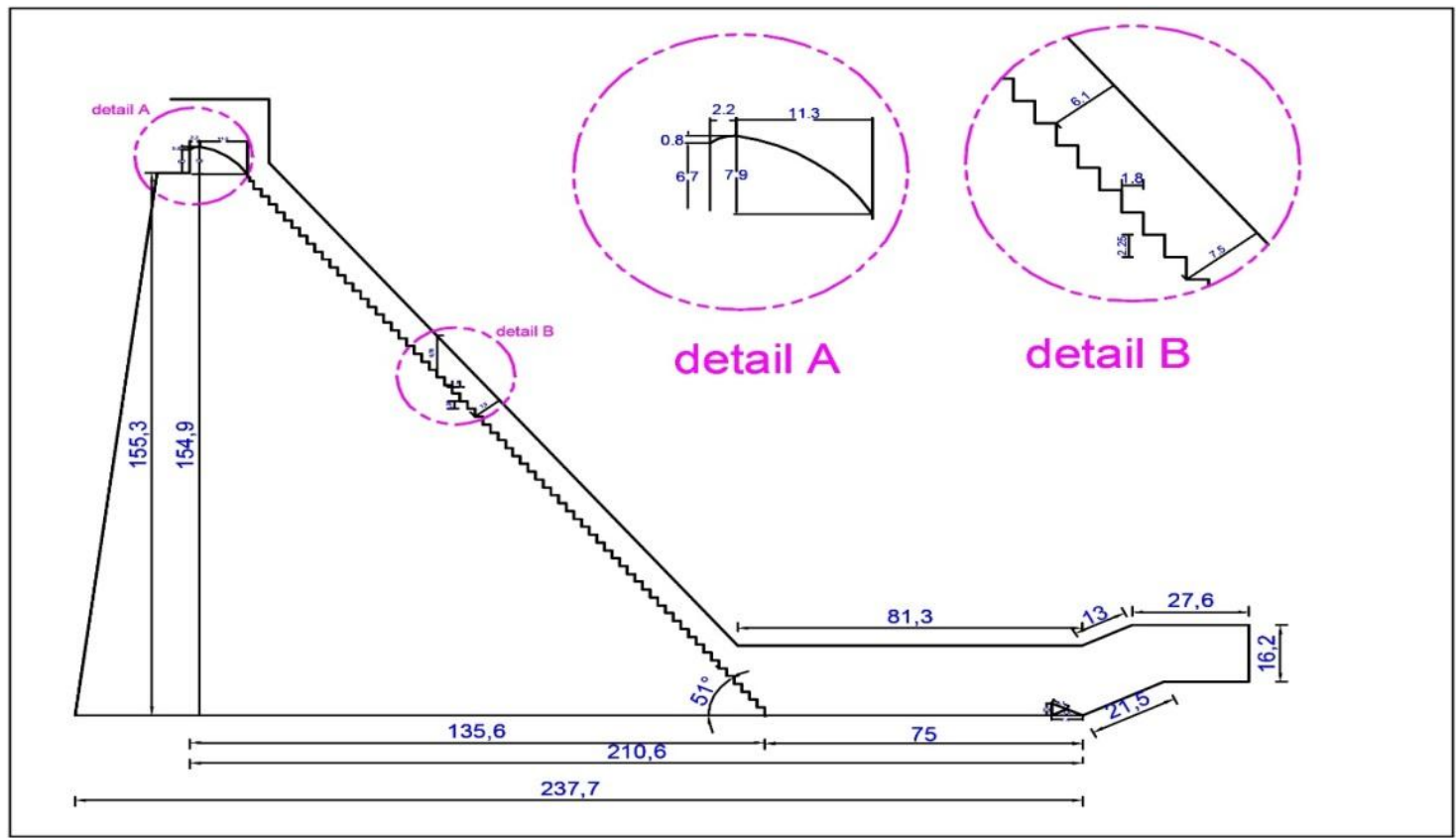

Fig. (3): The longitudinal section of the spillway model with a scale of 1:40 all dimensions are in centimetres.

Table (1): Characteristics of Bastora dam, spillway and stilling basin.

\begin{tabular}{lll}
\hline Dam characteristics & Type & RCC \\
\cline { 2 - 3 } & Crest elevation of the dam & $874 \mathrm{~m}$ \\
\cline { 2 - 3 } & Maximum water level & $871.811 \mathrm{~m}$ \\
\cline { 2 - 3 } & Normal water level & $868.5 \mathrm{~m}$ \\
\cline { 2 - 3 } & Minimum level of the river bed & $801.5 \mathrm{~m}$ \\
\cline { 2 - 3 } & Maximum height of the dam & $72.5 \mathrm{~m}$ \\
\cline { 2 - 3 } & Crest width & $10 \mathrm{~m}$ \\
\cline { 2 - 3 } & US slope of the dam & $0.125(\mathrm{H}): 1(\mathrm{~V})$ \\
\hline
\end{tabular}




\begin{tabular}{cll}
\hline & \multicolumn{1}{l}{ DS slope of the dam } & $0.8(\mathrm{H}): 1(\mathrm{~V})$ \\
\cline { 2 - 3 } & Total Storage & $80.8 \mathrm{MCM}$ \\
\hline Spillway characteristics & Crest Width & $25 \mathrm{~m}$ \\
\cline { 2 - 3 } & Crest elevation & $868.5 \mathrm{~m}$ \\
\cline { 2 - 3 } & Slope of chute canal & $0.8 \mathrm{H}: 1 \mathrm{~V}$ \\
\cline { 2 - 3 } & Design discharge & $313.15 \mathrm{~m}^{3} / \mathrm{sec}$ \\
\cline { 2 - 3 } & First step length & $0.24 \mathrm{~m}$ \\
\cline { 2 - 3 } & First step height & $0.3 \mathrm{~m}$ \\
\cline { 2 - 3 } & Second step length & $0.36 \mathrm{~m}$ \\
\cline { 2 - 3 } & Second step height & $0.45 \mathrm{~m}$ \\
\cline { 2 - 3 } & Rest step length & $0.72 \mathrm{~m}$ \\
\cline { 2 - 3 } $\begin{array}{c}\text { Stilling basin } \\
\text { characteristics }\end{array}$ & Rest step height & $0.9 \mathrm{~m}$ \\
\cline { 2 - 3 } & Type & $\mathrm{II}$ \\
\cline { 2 - 3 } & Length of stilling basin & $30 \mathrm{~m}$ \\
\cline { 2 - 3 } & Width of stilling basin & $26.5 \mathrm{~m}$ \\
\hline
\end{tabular}

Table (2): Dimensions of the chute stepped spillway model in centimetres The vertical height of the model (the difference between the crest and toe elevation) $162.8 \mathrm{~cm}$

\begin{tabular}{ll}
\hline The horizontal length between the upstream and downstream of model & $210.6 \mathrm{~cm}$ \\
\hline Crest width of model & $62.5 \mathrm{~cm}$ \\
\hline Slope of chute canal & $0.8 \mathrm{H}: 1 \mathrm{~V}$ \\
\hline No. of steps & 70 \\
\hline First step length & $0.6 \mathrm{~cm}$ \\
\hline First step height & $0.8 \mathrm{~cm}$ \\
\hline Second step length & $0.9 \mathrm{~cm}$ \\
\hline Second step height & $1.1 \mathrm{~cm}$ \\
\hline Length - the rest of the steps & $1.8 \mathrm{~cm}$ \\
\hline Height - The rest of the steps & $2.25 \mathrm{~cm}$ \\
\hline
\end{tabular}

supply water for the model and fixed to a steel frame. A V-notch weir is attached to the end of the tank to measure the outflow of the tank. A series of different mesh screens is fixed vertically in the overhead tank to reduce the turbulence and the power of the water pumped from underground storage tank to the overhead tank. Furthermore, as it can be seen in Figure 5 two control valves, one of $6 "$ in diameter and the other of 1.5 " in diameter, are used to control the discharge entering the tank.

The $90^{\circ} \mathrm{V}$-notch weir, which is shown in Figure 6, is used to measure the discharge over the stepped spillway. A small box tank is fixed and connected to the tank through an opening at the bottom, $80 \mathrm{~cm}$ above the $\mathrm{V}$-notch weir and on the right side of the overhead tank. A point gauge with a Vernier scale of $0.05 \mathrm{~mm}$ accuracy inside the box tank is used to measure the head of water over the V-notch. Thus, the water depth in the tank on the side is the same as in the overhead tank.

A tank with a capacity of 300 litters and inner dimensions of $1.5 \mathrm{~m}$ in length, $1 \mathrm{~m}$ in width and $0.3 \mathrm{~m}$ in height as illustrated in Figure 7 is fixed downstream of the weir to calibrate the headdischarge relation of the V-notch weir. The tank has three rollers on each side to ensure loose movement over the sides. At the downstream of the V-notch weir the tank is filled with water and a stop watch is used to record the lasting time. The time, the volume and the head above the V-notch are recorded during each test run. Also, as can be observed in Figure 8 an acrylic storage tank $(105 \mathrm{~cm}$ in length and $62.5 \mathrm{~cm}$ in width) is fixed on a steel frame at the upstream of the model. This tank is used to run water over the model. Two perforated acrylic plates $(62.5 \mathrm{~cm}$ in width each) are fixed across this tank to reduce the effect of the turbulent flow upstream of the spillway. 
A horizontal stilling basin $(75 \mathrm{~cm}$ in length, $66.25 \mathrm{~cm}$ in width) is attached to the base of the last step of the spillway. The downstream end of the basin is equipped with an end sill $(3.5 \mathrm{~cm}$ in height and $2.6 \mathrm{~cm}$ in width) as it is presented in Figure 9 . A channel $(8 \mathrm{~m}$ in length, $70 \mathrm{~cm}$ in width and $30 \mathrm{~cm}$ in height) is constructed from steel plates at the bottom of the model. As it is clear in Figure 10 this channel connects the stilling basin of the stepped spillways to the underground concrete storage tank in order to transfer and recirculate the water.

Tests are conducted, with discharge values varying from 2 lit/s to $41 \mathrm{lit} / \mathrm{s}$. The set of experiments consists of 24 runs. For each run, the water depth above the $\mathrm{V}$-notch weir and the corresponding steady flow and the uniform water depth in the tank at the upstream of the tested model are measured. Also, the critical flow depth over the weir crest is measured to check the amount of flow passing the model. Further, the flow depth above a number of steps along the chute depth slope is measured. Moreover, at relatively high discharges typical to the skimming flow regime the point of self-aeration is visually estimated as where white water initiates to be seen on the chute (Chanson, 2002). This allows us to measure both the flow depth at and length to that point. Finally, the post jump depth is measured at the end of the stilling basin to estimate the amount of energy dissipation for each run.

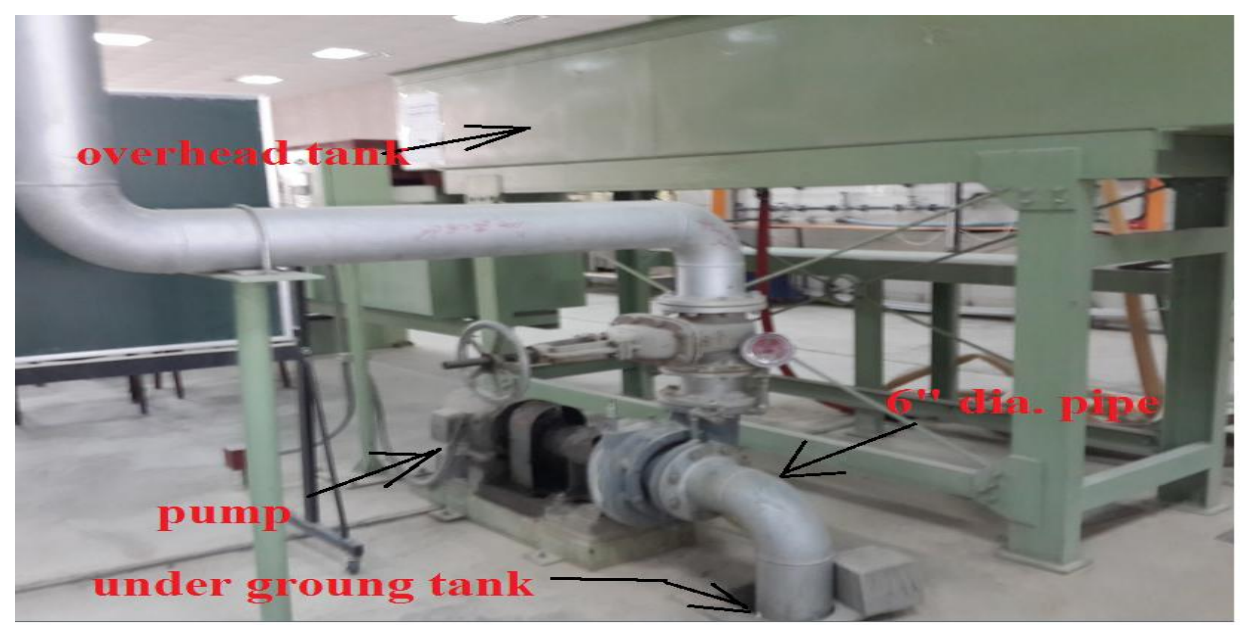

Fig. (4): The pump and the underground tank used in the study

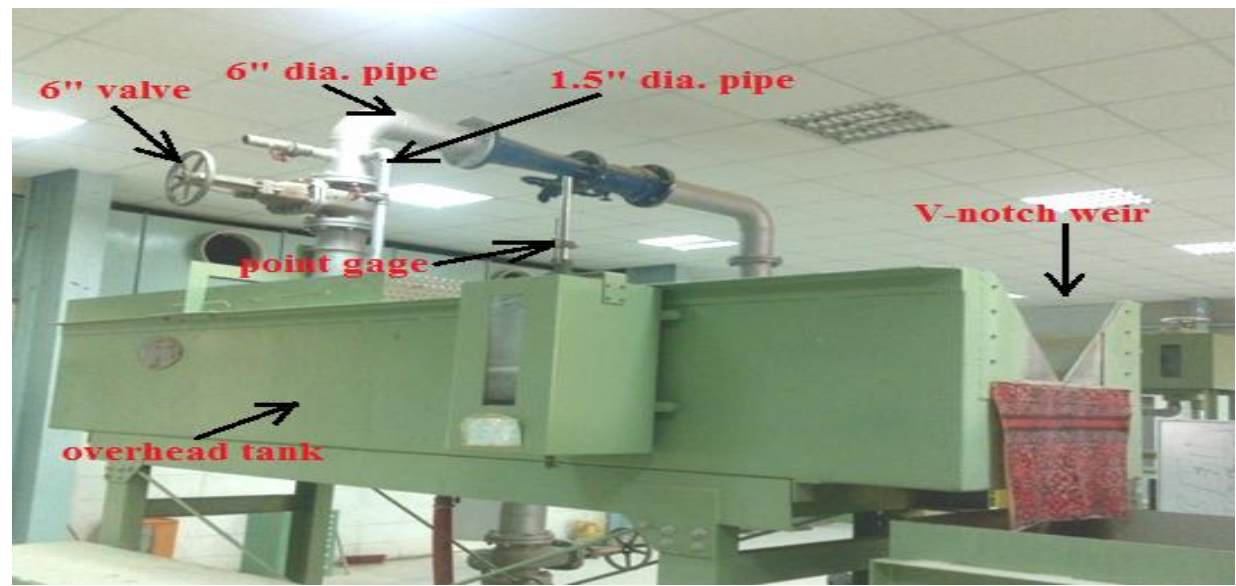

Fig. (5): The overhead tank and the V-notch weir used in the study 


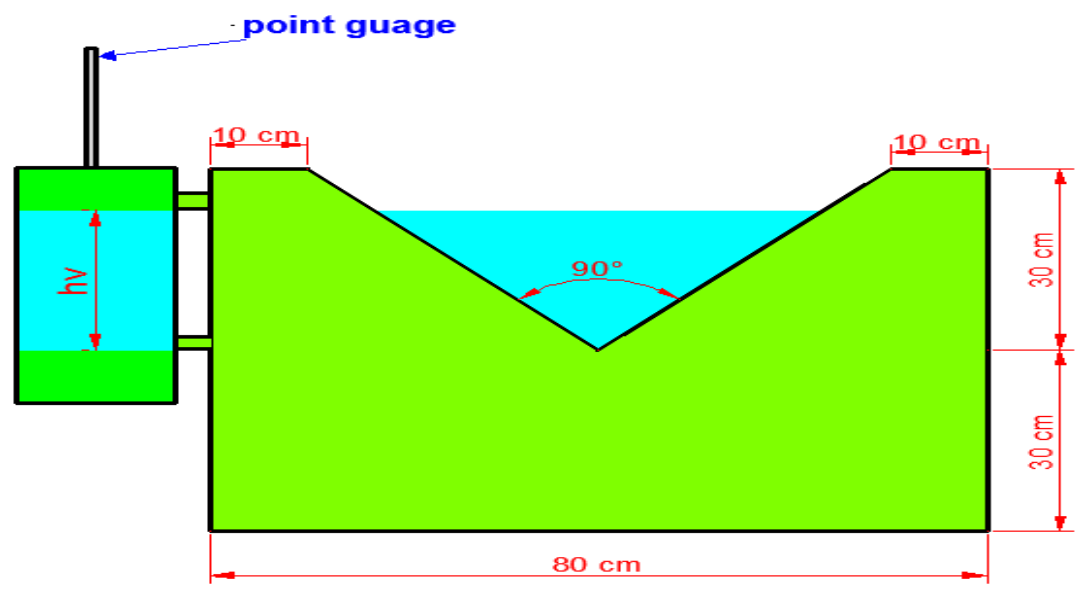

Fig. (6): Details of the V- notch weir used in this study

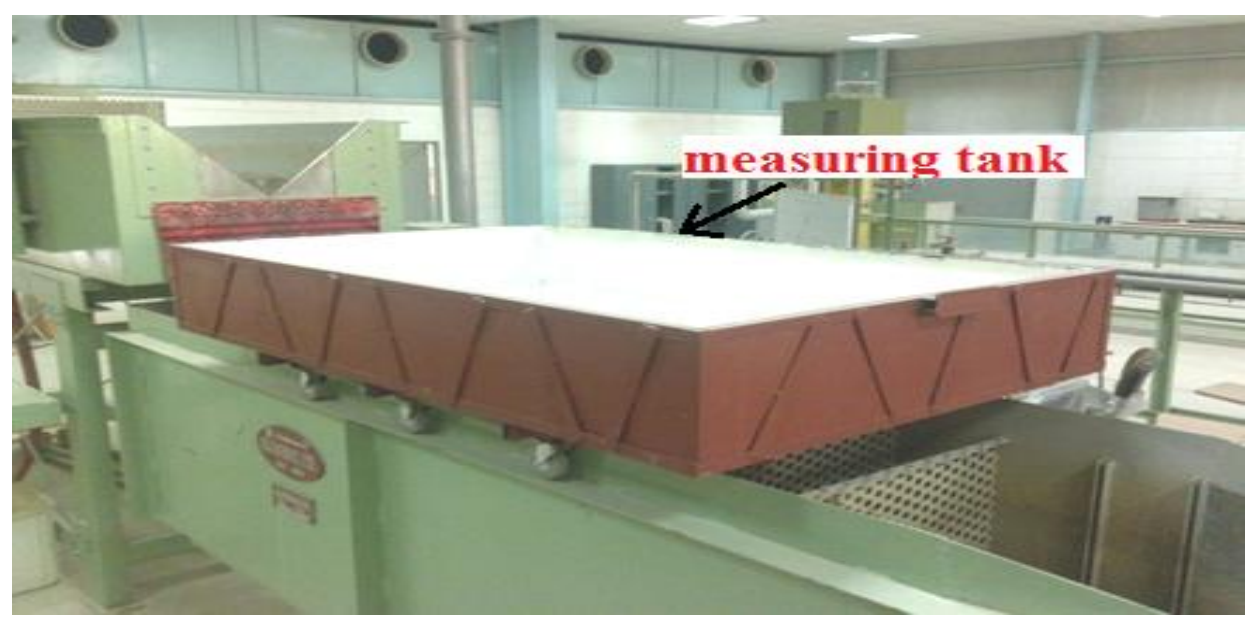

Fig. (7): The measuring tank used for the calibration of the V- notch weir

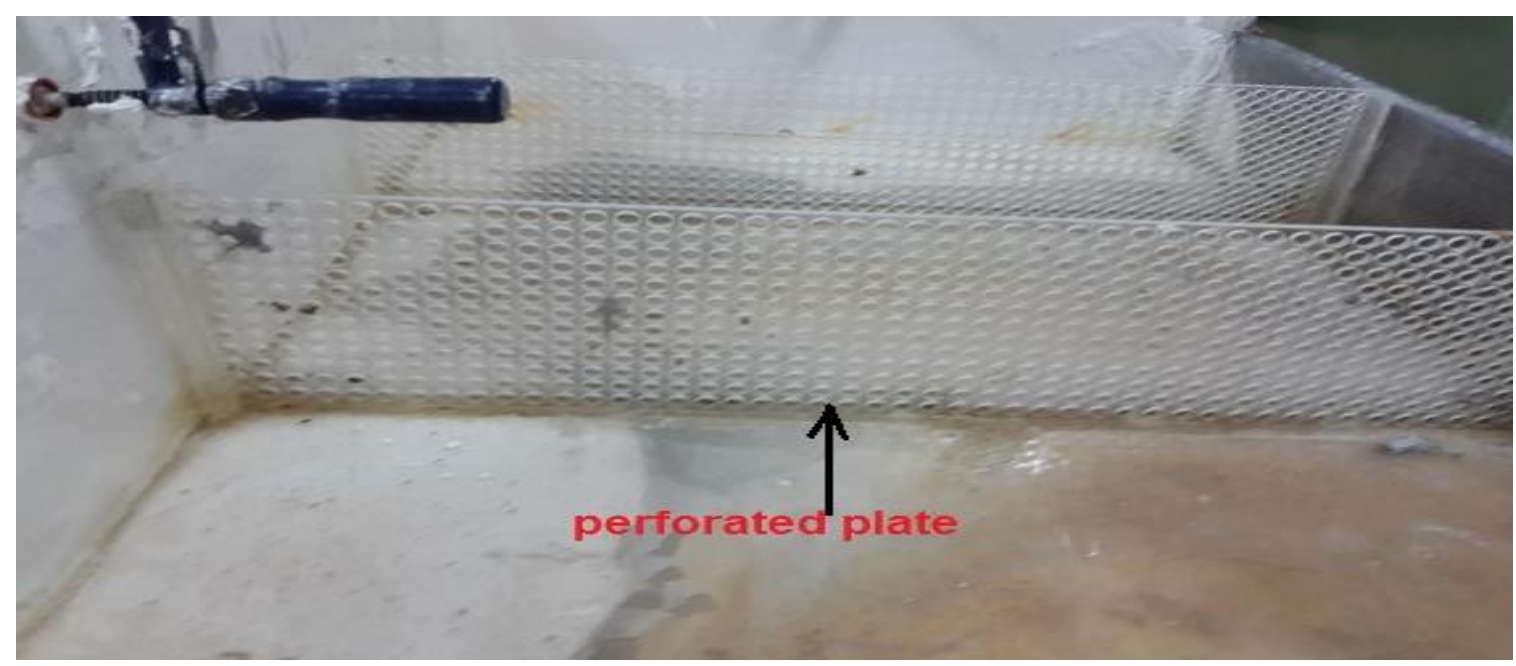

Fig. (8): Upstream storage tank with perforated acrylic plates 


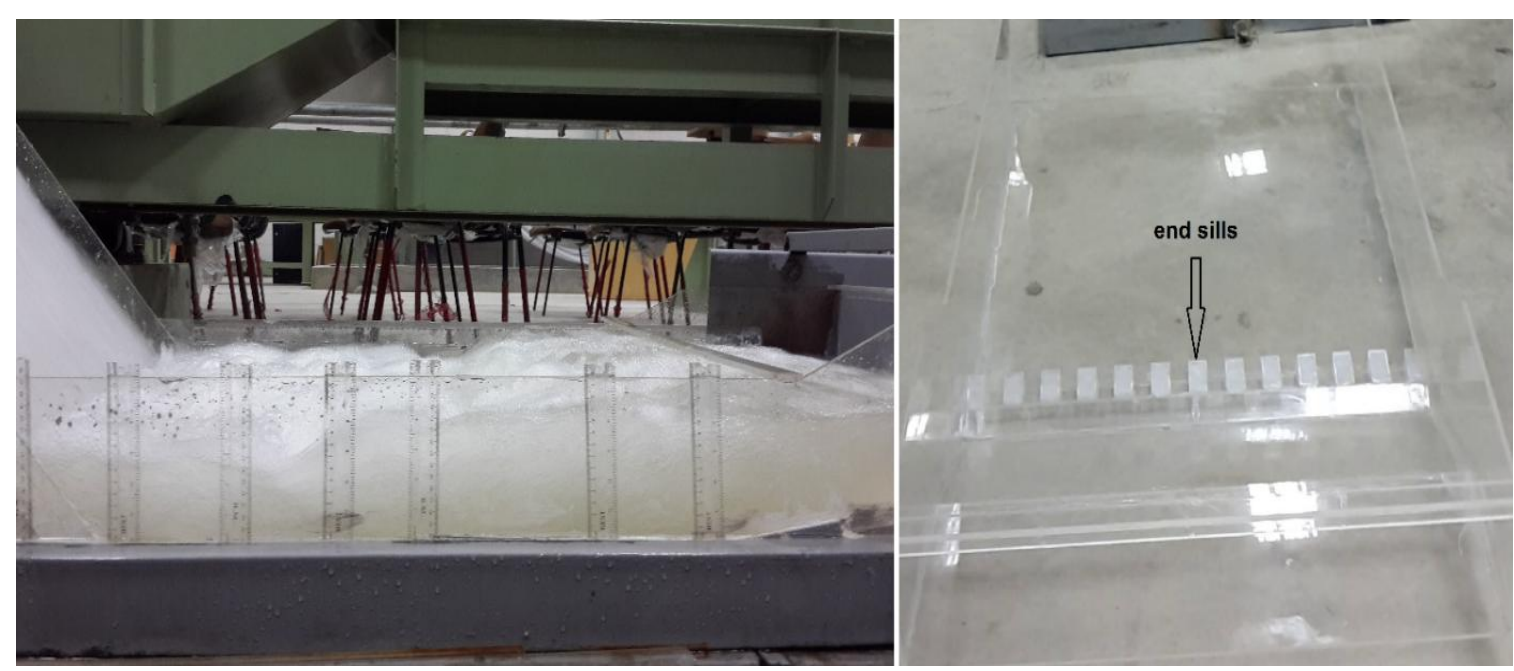

Fig. (9): Stilling basin at the end of the physical model

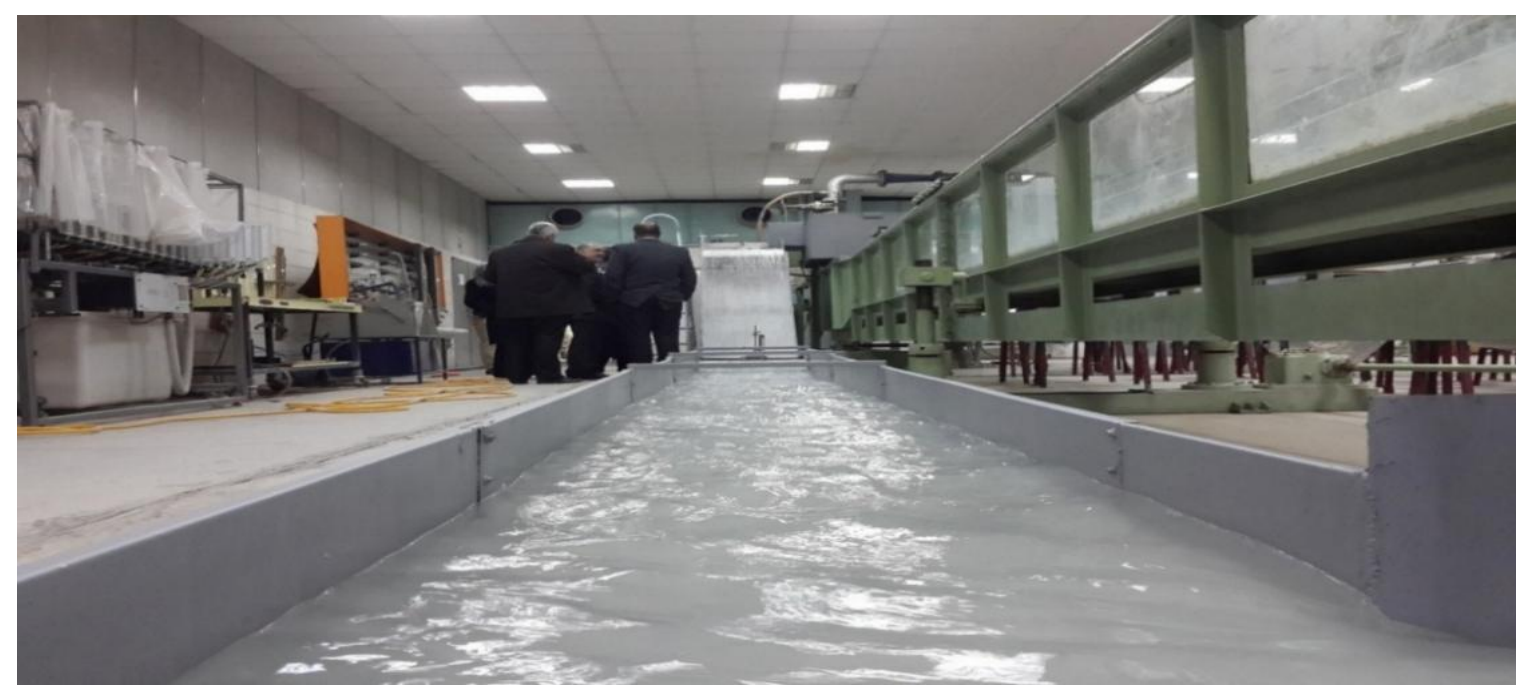

Fig. (10): The discharge channel during a test run

\section{RESULTS AND DISCUSSION}

In the present study, the hydraulic performance of a designed structure is evaluated in terms of the flow condition under which the spillway can be operated, the coordinate of inception point amount of air entrainment, energy dissipation rate, discharge coefficient and the size of the stilling basin.

Identifying the flow regime under which a stepped spillway operates is essential to determine whether cavitation is possible to occur or not, especially for relatively high discharges. This is because under such flow conditions the pressure acting on the vertical face of the steps close to the inception point of air entrainment may drop below the atmospheric pressure due to the increase of overflowing velocity (Frizzell and Renna, 2011), (Amador et al., 2009) and (Husain et al., 2013). In the physical model and based on visual observations, two main flow regimes on the stepped spillway were observed, namely; nappe and skimming flow. These observations were made according to the flow properties and descriptions presented in Chanson (2002).

For small flow rates water flow down the spillway as a series of free-falling nappes from one step to another. The air pocket was found near the corner of the tread and riser of the steps. However, with high flow rates water skimmed above the pseudo-bottom formed by the step edges. Also, two zones detected in skimming flow, non-aerated and aerated zones. In the nonaerated zone, which is started from the crest of spillway and extended to some distance along the slope, the water surface was fully smooth and without air entrainment. Then, the aerated flow region starts where large amount of air enters the 
flow due to the high degree of turbulence and white water can be clearly seen (Andre, 2004). These observations allow us to identify the upper and lower limits of the nappe and skimming flow condition over the Bastora stepped spillway in terms of the dimensionless parameter $\mathrm{y}_{\mathrm{c}} / \mathrm{h}_{\mathrm{s}}$, in which $y_{c}$ is the critical depth on the spillway crest and $h_{s}$ is the step height. Figures 11 and 12 are taken from the experiments conducted in the present study in which the nappe and skimming flow regime on the steps are respectively shown.

Table 3 compares the experimental results observed in this study with those reported in the design in terms of the upper limit of the nappe flow and lower limit of the skimming flow conditions. As it is clear there is a slight difference between them which can be attributed to the fact that equations (1) and (2), which are suggested by Chanson (2001) and derived taking into consideration a wide range of chute slopes $3.4^{\circ} \leq \theta$ $\geq 60^{\circ}$ and dimensionless flow rates $0.05 \leq \frac{\mathrm{h}_{\mathrm{s}}}{\mathrm{l}_{\mathrm{s}}} \leq$ 1.7 , are used in the design report to predict the flow condition, whereas the results of the present work are obtained from one chute slope of $\theta=$ $51.34^{\circ}$.
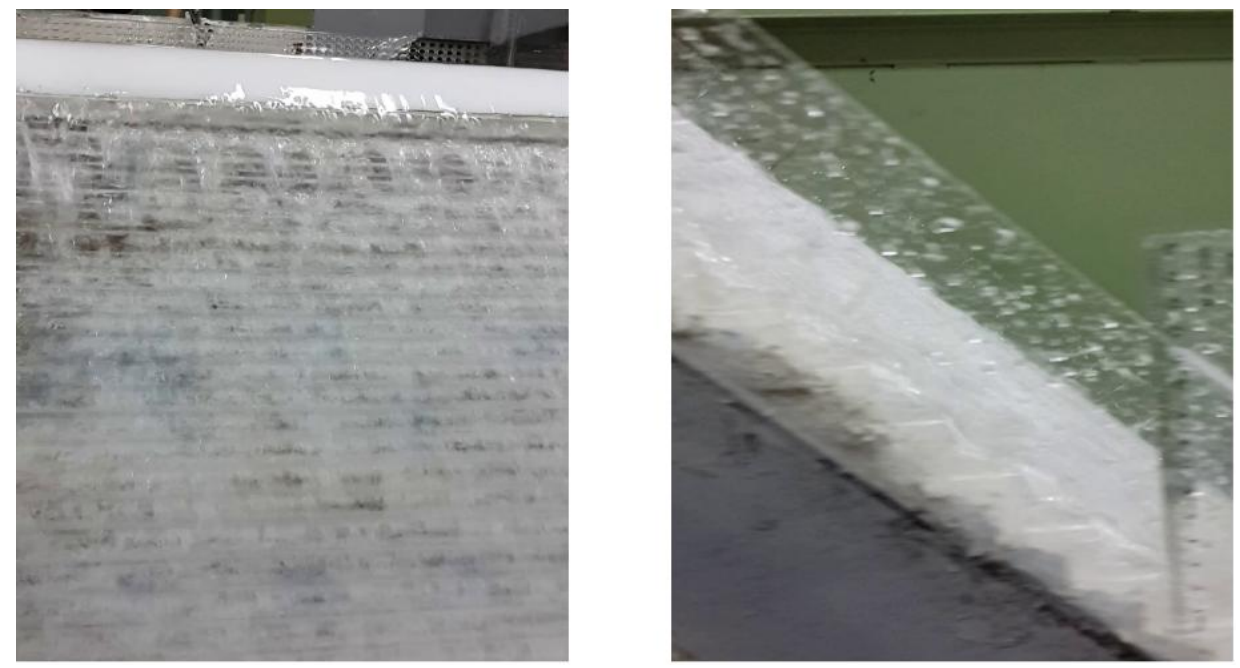

Fig 11. Nappe flow regime for low discharge 2 lit/sec.
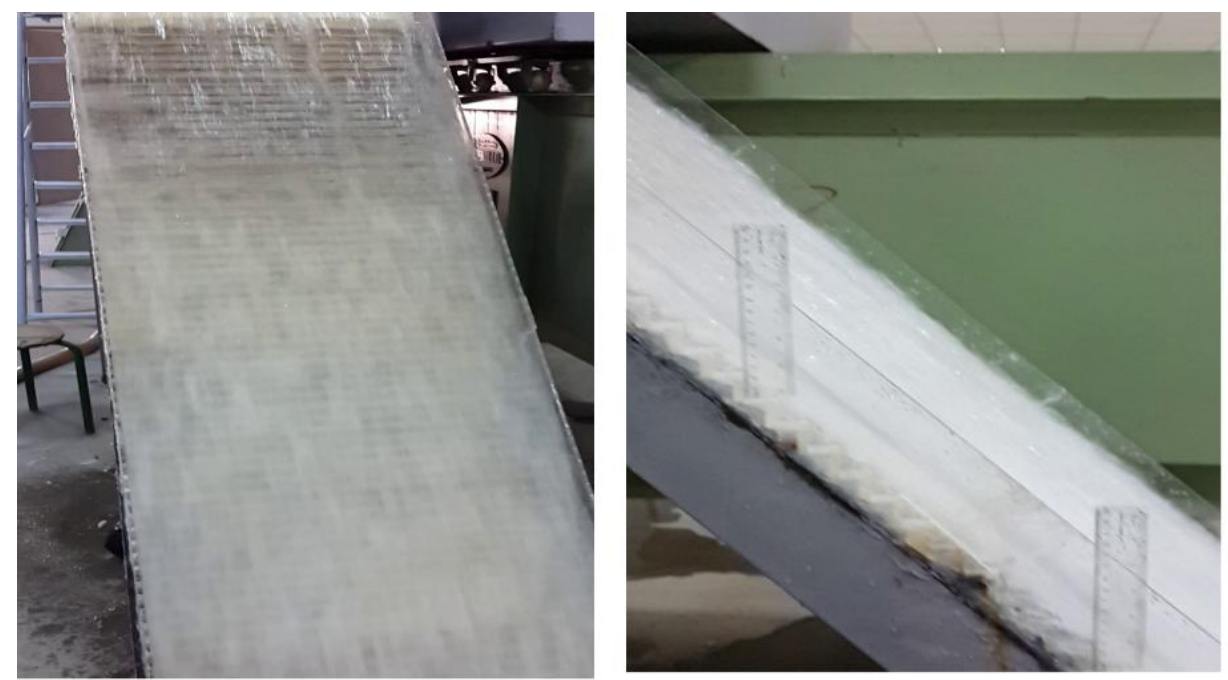

Fig 12. Skimming flow regime over the physical model at design discharge 31 lit/sec. 
Table (3): Comparison between the design report and physical model results in terms of predicting the nappe and skimming flow regimes.

\begin{tabular}{ccc}
\hline & \multicolumn{2}{c}{$\mathbf{y}_{\mathbf{c}} / \mathbf{h}_{\mathbf{s}}$} \\
\cline { 2 - 3 } & Upper limit of nappe flow & lower limit of skimming flow \\
\hline Physical model & 0.533 & 0.711 \\
\hline design report & 0.39 & 0.79 \\
\hline
\end{tabular}

The length to and depth at the inception point of self-aeration are also measured in the present study and compared with the corresponding ones determined in the design report. The location of this point is necessary for the designer of stepped spillways, especially at the design discharge. This is because as pointed out by Frizzell and Mefford (1991), Amador et al. (2009) and Frizzell and Renna (2011) the upstream portion of this point is likely prone to cavitation damage. In the present study, the coordinate of the inception point of selfaeration is measured on the physical model for the maximum design discharge of $31 \mathrm{lit} / \mathrm{s}$. It is observed that white water starts to occur at step number 20 from the top. In the current work the length to and flow depth at the inception point are measured for maximum design discharge and found to be $L_{i}=0.6697 \mathrm{~m}$ and $d_{i}=0.0265 \mathrm{~m}$, while in the design report the relations (3) and (4) suggested by Boes \& Minor (2002) are used to find the corresponding flow characteristics at the inception point, which are determined to be $L_{i}=$ $0.62 \mathrm{~m}$ and $d_{i}=0.024 \mathrm{~m}$. The differences in both results may be due to the fact that in the design report equations 3 and 4 , which are recommended by Boes \& Minor (2002) and originally derived on a number of chutes having bottom slopes ranging between 27 and $75^{\circ}$, are used to determine the location of this point on the structure. While, in this study the flow characteristics at this point are measured experimentally on a chute of bottom slope of $53^{\circ}$.

The efficiency of Bastora dam stepped spillway is also evaluated in this study in terms of the amount of energy dissipation at its end and compared with those proposed in the design report. The amount of energy dissipation is estimated at two locations one is at the end of the stilling basin and the other one is at the end of the chute. For this purpose, experiments with different flow rates are conducted from which flow depths at the upstream and downstream of the model are measured and the corresponding mean flow velocities are determined. Also, equations 5, 6 and 7 are used to estimate and calculate the amount of energy dissipation rate. The percentage of dissipated energy $\left(\Delta \mathrm{H} / \mathrm{H}_{1}\right)$ in each run is determined and plotted against the discharge tested in this study and shown in Figure 13. $\Delta \mathrm{H}$ represents the amount of energy that is dissipated between the upstream of the spillway crest $\mathrm{H}_{1}$ and the section $\mathrm{H}_{\mathrm{i}}$ under consideration at the downstream. The results show that the energy dissipation decreases as discharge increases, which is compatible with previous studies on stepped spillways (Karim K.E and Mariam K A., 2009), (Roshan et al., 2010), (Felder and Chanson, 2011) and (Chatila et al., 2004). The total percent of energy dissipated is $90 \%$ at the design discharge, while the calculated total percent of the dissipated energy as presented in the design report is $67.3 \%$. This is because the designer uses the empirical equation provided by (Yasuda et al., 2001) which assumes that the flow attains to its normal depth at the end of the chute slope regardless of the flow regime. Recalculating the energy dissipation based on the elevations given in design report for the spillway before the jump and at end of the jump yields the following results.

Spillway crest level $=868.5 \mathrm{~m}$.

Effective head $=3.31 \mathrm{~m}$.

Upstream total energy line $=871.81 \mathrm{~m}$.

Elevation of the stilling basin $=803 \mathrm{~m}$.

Water level after the jump $=809.816 \mathrm{~m}$.

Head due to velocity $=0.153 \mathrm{~m}$.

Downstream total energy line $=809.969 \mathrm{~m}$.

Thus,

Total percent of energy dissipated = $\frac{871.81-809.969}{871.81-803} * 100=89.87 \%$.

This value is identical to that obtained in this study on the physical model.

The energy dissipation rate at the end of the chute slope is also calculated in the present work. To do so, the amount of energy dissipation and residual energy are calculated at the last step for the chute channel and the results are shown in 
Figure 14. The results demonstrate that at low discharges most of the flow energy is dissipated over the steps, because each step acts as a small stilling basin resulting in reaching the percentage of dissipated energy at the end of the chute to $89.1 \%$. However, the amount of percentage of energy dissipation rate according to the design report is

$67.3 \%$.

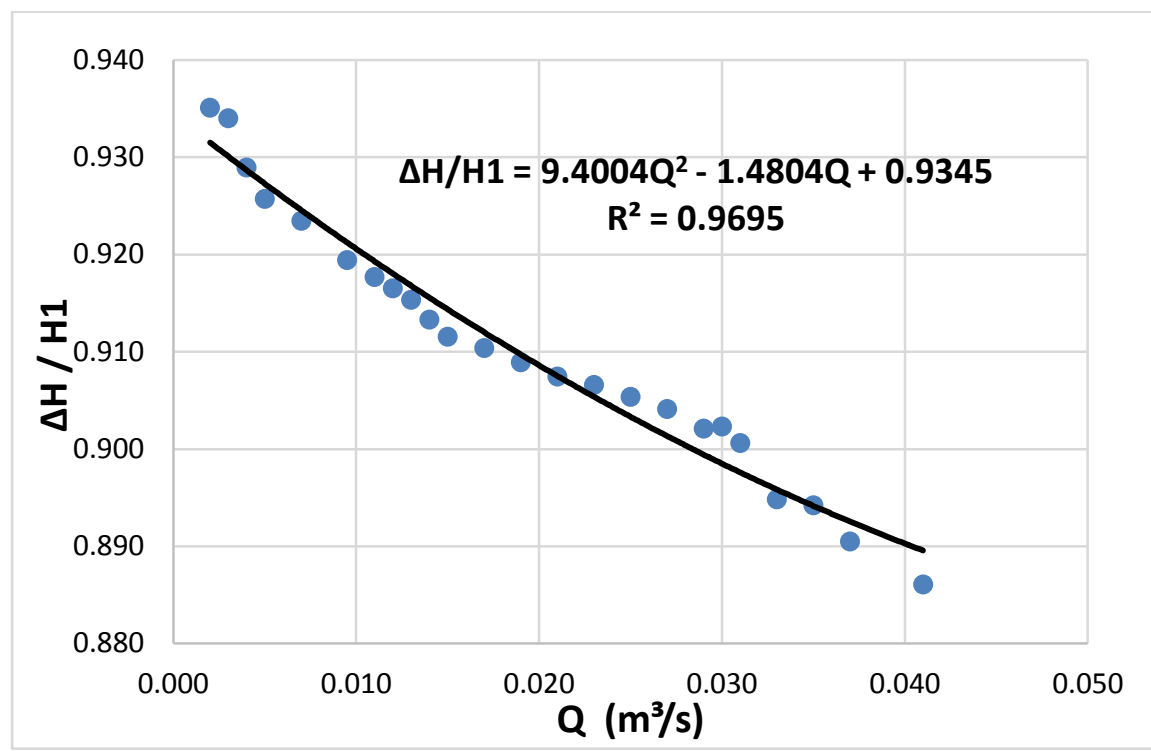

Fig. (13): Total energy dissipation rate of flow over the stepped spillway versus discharge.

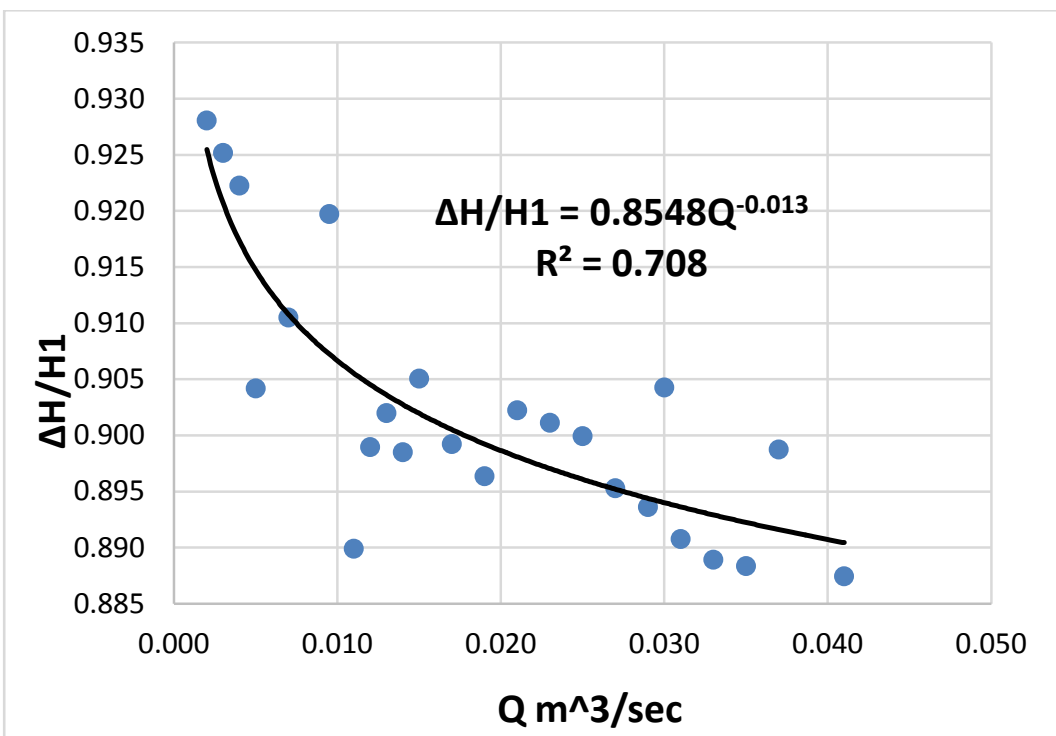

Fig. (14): The energy dissipation between upstream and end of the chute stepped spillway versus discharge.

Research into the size of the stilling basin and side walls of the chute is somewhat lacking. However, in this study the size of the stilling basin in terms of its length, free board for both the basin and side walls is calculated and compared with the corresponding ones reported in the proposed design project. The results of these design parameters are tabulated in Table 4. The design report used the following equation to calculate the length of the stilling basin, which is assumed to be the same at that of the hydraulic jump length for maximum design discharge, as proposed by Modi (1995):

$\mathrm{L}_{\mathrm{j}}=4.2 * \mathrm{y}_{2}$

8

in which $L_{j}$ is the length of the stilling basin. Which is considered to be identical to the jump 
length, and $y_{2}$ is the depth of water at the downstream of the hydraulic jump. In addition, the following empirical equation is used in the design report to find out the free board for the side walls of the stilling basin.

Free board $=0.6+0.03731 * V$

$$
* d^{\frac{2}{3}} \quad 9
$$

where, $v$ and $d$ are respectively the mean flow velocity and depth at the stilling basin. The same equation is used herein to find the free board required for the side walls of the stilling basin by measuring the actual mean flow depth and calculating the mean flow velocity for the maximum design discharge. However, the free board for the side walls of the chute is determined using the formula given by Boes and Hager (2003) and defined as follows:
$\frac{\mathrm{Y}_{90}}{\mathrm{~K}_{\mathrm{S}}}=0.5 \cos \theta^{1.5(0.1 \tan \theta+0.5)} \mathrm{F}_{\mathrm{r}}(0.1 \tan \theta+0.5)$
$/ \cos \theta \quad 10$

in which, $y_{90}$ is the flow depth where the air concentration is $90 \%, K_{s}$ is the roughness height measured perpendicular on the flow direction and defined as $h_{s} \cos \theta, h_{s}$ is the step height, $\theta$ is the chute slope and $F_{r}$ is the Froude number. Equation 10 is used in the current work to find the free board required for the side walls of the chute under the same flow conditions. Table 5 presents a number of design parameters for the stilling basin and side walls of the chute presented in the design report and compared them with those predicted in this study. As it is obvious, despite some differences between both results, the agreement is fairly

good.

Table (5): Comparison between the results of design report and physical model in terms of design parameters at the stilling basin.

\begin{tabular}{lcc}
\hline & According to design report & According to physical model \\
\hline Length of stilling basin & $30 \mathrm{~m}$ & $27.72 \mathrm{~m}$ \\
\hline Free board for stilling basin & $0.833 \mathrm{~m}$ & $0.835 \mathrm{~m}$ \\
\hline $\mathrm{Y}_{90}$ & $1.231 \mathrm{~m}$ & $1.072 \mathrm{~m}$ \\
\hline Free board for side wall & $1.169 \mathrm{~m}$ & $1.328 \mathrm{~m}$ \\
\hline
\end{tabular}

As mentioned earlier the discharge coefficient is considered in this study to evaluate the performance of Bastora dam stepped spillway as it affects the length of the spillway. In the design report the discharge coefficient $C_{d}$ is estimated to be 2.136 at the design discharge without considering the effect of the approach velocity head $v^{2} / 2 g$ by using the following equation:

$Q=C_{d} L H_{d}^{\frac{3}{2}}$

where, $L$ is the spillway crest width and $H_{d}$ is the total upstream head of water at the design discharge.

The approach velocity head can be neglected when the ratio between the total upstream head and the spillway height is less than 0.5 (Subramanya, 1982). However, in the present study two cases are examined to calculate the value of discharge coefficient $C_{d}$. In the first case the value of $v^{2} / 2 g$ is neglected in calculating the total upstream head, whereas, in the second case it's value is considered. It should be noted here that the total upstream head in this research is calculated by measuring the actual depth of water above the spillway crest for the design discharge passing it. For both cases, it is observed that the discharge coefficient is 2.140 and 2.255 respectively. This indicates that the discharge coefficient determined in this study is close to that reported in the design report when the approach velocity head at the upstream is neglected in calculating the total upstream head above the crest. This can be attributed to the fact that the ratio of the total head above the crest at the design discharge to the spillway height is less than 0.5.

\section{CONCLUSIONS}

The hydraulic performance of Bastora dam stepped spillway is evaluated experimentally by constructing a physical model using suitable scale ratio. A comparison between the results obtained from the physical model and those reported in the design report has been carried out to evaluate the performance of the structure. Despite the fact that some differences between both results are determined in particular in terms of the amount of energy dissipation rate and free board for the side walls, the overall design report can be considered reliable. However, the safety of the structure is still needed to be investigated against the potential 
of cavitation damage which may occur during the maximum design discharge. This requires analysing the pressure and velocity flow fields on the vertical face of steps located in the non-aerated flow region close to the spillway crest.

\section{REFERENCES}

- Amador, A., Sanchez-Juny, M. and Dolz, J. (2009). Developing flow region and pressure fluctuations on steeply sloping stepped spillways. Journal of Hydraulic Engineering, 135(12), 1092-1100.

- André, S. (2004). High velocity aerated flows on stepped-chutes with macro-roughness elements. Communication 20, (2004), Laboratorie de Constructions Hydrauliques Ecole Polytechnique Federale de Lausanne: Lausanne, Switzerland. ISSN 1661-1179.

- Boes, R. M. and Hager, W. H. (2003). Hydraulic design of stepped spillways. Journal of Hydraulic Engineering, 129(9), 671-679.

- Boes, R. and Minor, H. E. (2002). Hydraulic design of stepped spillways for RCC dams. International Journal on Hydropower and Dams, 9(3): pp.87-91.

- Carvalho, R. F. and Martins, R. (2009). Stepped spillway with hydraulic jumps: application of a numerical model to a scale model of a conceptual prototype. Journal of hydraulic engineering, 135(7), 615-619.

- Chamani, M. R. and Rajaratnam, N. (1999). Characteristics of skimming flow over stepped spillways. Journal of Hydraulic Engineering, 125(4), 361-368.

- Chanson, H. (1993). Stepped spillway flows and air entrainment. Canadian Journal of Civil Engineering 20, 422-435.

- Chanson, H. (1994). Hydraulics of skimming flows over stepped channels and spillways Journal of Hydraulic Research, 32(3), 445-460.

- Chanson, H. (1996). Prediction of the transition nappe/skimming flow on a stepped channel. Journal of Hydraulic Research, IAHR, 34(3), 421-429.

- Chanson, H. (1997). Air bubble entrainment in freesurface turbulent shear flows. Academic Press.

- Chanson, H. (2000). Characteristics of Skimming Flow over Stepped Spillways. Journal of Hydraulic Engineering, 126(11), 862-865.
- Chanson, H. (2001). Hydraulic design of stepped spillways and downstream energy dissipators. Journal of Dam Engineering, 11(4), 205-242.

- Chanson, H. (2002). Hydraulics of stepped chutes and spillways. Lisse: A.A. Balkema publishers, CRC Press.

- Chanson, H., and C. Gonzalez (2005). Physical modelling and scale effects of air-water flows on stepped spillways. Journal of Zhejiang UniversityScience, A 6(3), 243-250.

- Chanson, H., Yasuda, Y., and Othsu, I. (2002). Flow resistance in skimming flows in stepped spillways and its modelling. Canadian Journal of Civil Engineering, 29(6), 809-819.

- Chatila, J. G., and Jurdi, B. R. (2004). Stepped spillway as an energy dissipater. Canadian Water Resources Journal, 29, 147-158.

- Chow, V. T. (1959). Open channel hydraulics. McGraw-Hill, New York, USA: McGraw-Hill,

- Felder, S., \& Chanson, H. (2011). Energy dissipation down a stepped spillway with non-uniform step heights. Journal of Hydraulic Engineering, 137(11), 1543-1548.

- Frizzell, K. H., and Mefford, B. W. (1991). Designing Spillways to Prevent Dam cavitation. Concrete International, 13(5), 58-64.

- Frizzell, K. and Renna, F. M. (2011). Laboratory Studies on the Cavitation Potential of Stepped Spillways [online]. In: Valentine, EM (Editor); Apelt, CJ (Editor); Ball, J (Editor); Chanson, H (Editor); Cox, R (Editor); Ettema, R (Editor); Kuczera, G (Editor); Lambert, M (Editor); Melville, BW (Editor); Sargison, JE (Editor). Proceedings of the 34th World Congress of the International Association for Hydro- Environment Research and Engineering: 33rd Hydrology and Water Resources Symposium and 10th Conference on Hydraulics in Water Engineering. Barton, A.C.T.: Engineers Australia, 2011: 2420-2427.

- Hunt, S. L. and Kadavy, K. C. (2010). Energy dissipation on flat sloped-stepped spillway: I. Upstream of the inception point. Transactions of the American Society of Agricultural and Biological Engineers, ASABE, 53(1), 103-109.

- Hunt, S., Reep, D. and Kadavy, K. C. (2008). RCC stepped spillways for Renwick dam-a partnership in research and design. Dam Safety Journal, 6(2), 32-40.

- Hunt, S. and Kadavy, K. C. (2010). Energy dissipation on flat sloped-stepped spillway: I. Upstream 
of the inception point. Transactions of the American Society of Agricultural and Biological Engineers, ASABE, 53(1), 103-109.

- Husain, S. M., Muhammed, J. R., Karunarathna, H. U., \& Reeve, D. E. (2014). Investigation of pressure variations over stepped spillways using smooth particle hydrodynamics. Advances in Water Resources, 66, 5269.

- Peyras, L., Royet, P. and Degoutte, G. (1992). Flow and energy dissipation over stepped gabion weirs. Journal of Hydraulic Engineering, ASCE, 118 (5), 707 717.

- Rajaratnam, N. (1990). Skimming flow in stepped spillways. Journal of Hydraulic Engineering 116, $587-$ 591.

- Rice, C. E. and Kadavy, K. C. 1996. Model study of a roller compacted concrete stepped spillway. Journal of Hydraulic Engineering, ASCE, 122(6), 292-297.
- Roshan, R., Azamathulla, H. M., Marosi, M., Sarkardeh, H., Pahlavan, H., \& Ab Ghani, A. (2010). Hydraulics of stepped spillways with different numbers of steps. Journal of Dams and Reservoirs, 20(3), 131136.

- Sanchez-Juny, M., E. Blade, et al. (2008). Analysis of pressures on a stepped spillway. Journal of Hydraulic Research, 46, 410-414.

- Subramanya, K. (1982). Flow in Open Channels (3e). Tata McGraw-Hill Education.

- Takahashi, M., Gonzalez, C. A., \& Chanson, H. (2006). Self-aeration and turbulence in a stepped channel: Influence of cavity surface roughness. International journal of multiphase flow, 32(12), 1370-1385.

- Yasuda, Y., Takahashi, M., \& Ohtsu, I. (2001). Energy dissipation of skimming flows on steppedchannel chutes. Proceedings of $29^{\text {th }}$ IHAR Congress, (pp.531-536), Beijing, China. 